\title{
EDITORIAL
}

\section{Fluid management in the ICU: has the tide turned?}

\author{
Peter Buhl Hjortrup ${ }^{1 *}$ and Anthony Delaney ${ }^{2,3,4}$
}

๑ 2016 Springer-Verlag Berlin Heidelberg and ESICM

In 1832, Thomas Latta successfully administered intravenous fluid to patients with severe dehydration who had contracted cholera during the pandemics of the 19th century, the first recorded successful application of "saline drip" methodology [1]. More than 150 years hence, fluid management remains a core task for clinicians in intensive care units (ICU). The indications for fluid therapy have expanded greatly and are now used not only to treat significant fluid losses, but also to avoid fluid depletion (so-called maintenance fluid) and as a means of delivering medication, electrolytes and nutrition. Perhaps the most common use of fluids in the ICU is to "optimise the circulation" in patients with suspected haemodynamic compromise. Fluid management in the ICU involves not only the management of fluid input but also the management of fluid output, including the administration of diuretics and, in the case of severe kidney failure, dialysis. Current thinking regarding fluid management might be well represented by the Surviving Sepsis Campaign guideline for continued fluid therapy beyond an initial challenge: 'Fluid challenge technique be applied wherein fluid administration is continued as long as there is hemodynamic improvement either based on dynamic or static variables' [2]. The wording of this recommendation puts more emphasis on the potential benefit than the potential harm of fluids and arguably promotes the liberal use of fluids. This is in keeping with the common view of clinicians, who have tended to focus more on the risks to patients of being fluid deficient than on the risks of being fluid overloaded.

In a recent article in Intensive Care Medicine, Silversides and colleagues present the results of a systematic

\footnotetext{
*Correspondence: Peter.Buhl.Hjortrup@regionh.dk

1 Department of Intensive Care, Copenhagen University Hospital

(Rigshospitalet), Copenhagen, Denmark

Full author information is available at the end of the article
}

review and meta-analysis of fluid management beyond initial resuscitation in patients with acute respiratory distress syndrome (ARDS) and sepsis [3]. The systematic review was performed according to high methodological standards, including a pre-published protocol [4]. The authors chose a broad search strategy to minimise the risk of missing relevant studies and consequently screened more than 60,000 abstracts. Commendably, the meta-analysis was restricted to the randomised controlled trials (RCTs) included in the review, with observational studies still reported, albeit separately. There were also noteworthy limitations. First, most likely due to an a priori expectation of limited data from RCTs, the authors chose to include studies on both ARDS and sepsis. However, ARDS and sepsis, although not mutually exclusive, are two distinct clinical entities; as such, performing a meta-analysis of results on both clinical entities together introduces clinical heterogeneity. Additional heterogeneity is introduced with the inclusion of both adult and paediatric patient populations. Second, the concepts of 'conservative' and 'liberal' are arbitrary and varied between studies; significant differences between these strategies within the included RCTs were often not evident. Last, most of the included studies used protocols that were not reflective of daily practice where the most common indications for fluid administration are easily available measures, such as arterial blood pressure, urinary output, vasopressor dose and lactate $[5,6]$. This limitation reduces the clinical applicability of trial results.

Although not unexpected, the most noteworthy aspect of the review by Silversides and colleagues was not what they found, but rather what they did not find [3]. Despite broad inclusion criteria and a comprehensive search strategy, only $11 \mathrm{RCTs}$ were included in the meta-analysis, with a median of 100 included patients. Of these, only two RCTs were performed in more than two centres $[7,8]$. In their meta-analyses of the primary

\section{Springer}


Table 1 Unanswered questions in fluid management to be addressed in future trials

\begin{tabular}{|c|c|}
\hline Aspects of fluid management & Unanswered questions \\
\hline Fluids to "optimise the circulation" & $\begin{array}{l}\text { What level of circulatory impairment requires intervention with fluids and which } \\
\text { measures of impairment are most useful? } \\
\text { Do fluid responders benefit from fluids? } \\
\text { Do fluids alleviate or cause acute kidney injury? } \\
\text { Do the effects of fluid depend on timing rather than indication? }\end{array}$ \\
\hline Fluids to replenish losses & $\begin{array}{l}\text { How to assess fluid status? } \\
\text { Does'intravascular fluid depletion' merit fluid administration? }\end{array}$ \\
\hline Fluids to maintain a fluid balance & $\begin{array}{l}\text { Is maintenance fluid beneficial? } \\
\text { What is the minimum amount of fluid that patients should receive daily? }\end{array}$ \\
\hline Fluids along other therapies (e.g. medication and nutrition) & Is it beneficial to limit fluid content? \\
\hline
\end{tabular}

outcome, mortality, the authors found a relative risk of mortality for conservative versus liberal of 0.92 (95\% confidence interval 0.82-1.02); albeit non-significant, this result raises concerns with the paradigm that a liberal fluid strategy is beneficial-or benign at worst. In the analysis of the secondary outcome, ventilator-free days (VFD), the authors found a significantly higher number of VFD in patients assigned to restrictive groups, a result that was mostly driven by the FACTT trial which had complex protocols in both intervention groups [8]. A recent meta-analysis that included observational studies reported significantly lower mortality in restrictive strategies [9], but the results obtained by Silversides and colleagues should be regarded as more valid due to the risk of bias in observational studies-especially confounding by indication, competing risks and time-dependency.

Evidence is emerging to assist clinicians in making decisions about how to manage fluid balance in critically ill patients. The initial resuscitation in septic shock has been studied in three high-quality, large-scale trials, but fluid resuscitation was only one part of the intervention, together with vasopressors, red blood cell transfusions and dobutamine [10-12], which hampers inference about fluid volumes specifically. In children with severe infection, the FEAST trial illustrated that in a resource-limited setting, a single fluid bolus can be detrimental [13]. This systematic review highlights the current lack of data in the fluid management of patients with ARDS and sepsis beyond initial management. Due to the complexities of fluid management, a single definitive trial is unlikely, if not utopian. Thus, many unanswered questions remain. Fluids are administered under many circumstances, and each of these is likely to have a different balance between benefits and harms (Table 1). The concept of fluid responsiveness has been intensely studied in the literature [14], and the search for the optimal predictor of fluid responsiveness is ongoing. However, even in the cases of fluid responders, it is not known whether fluids are beneficial, neutral or harmful. These questions still deal only with the issue of fluid volume and fluid balance and do not touch the related and also complex issues regarding fluid composition. Given the ubiquitous nature of fluid management in the ICU, it is a major problem that the evidence base to guide clinicians is so limited.

In summary, although we are approaching the bicentennial of intravenous fluid therapy, considerable gaps in our knowledge persist. Results from observational studies and meta-analyses of RCTs suggest that liberal fluid management might be harmful to patients, but the interpretation of these results is hampered by complex protocols and substantial clinical heterogeneity. For many years, the standing paradigm in the management of the critically ill has been to ensure patients are not fluid deficient, with less attention paid to the problems related to fluid overload. This meta-analysis by Silversides and colleagues may represent the high water mark, and with the turning tide we can seek a more balanced approach to fluid management in the critically ill.

\section{Author details \\ ${ }^{1}$ Department of Intensive Care, Copenhagen University Hospital (Rigshospi- talet), Copenhagen, Denmark. ${ }^{2}$ Malcolm Fisher Department of Intensive Care Medicine, Royal North Shore Hospital, St. Leonards, NSW, Australia. ${ }^{3}$ Northern Clinical School, Sydney Medical School, University of Sydney, St. Leonards, NSW, Australia. ${ }^{4}$ ANZICS Research Centre, School of Public Health and Preven- tative Medicine, Monash University, Melbourne, Australia.}

\section{Compliance with ethical standard}

Conflicts of interest

The authors have no conflicts of interest to declare.

Received: 18 October 2016 Accepted: 19 October 2016

Published online: 31 October 2016

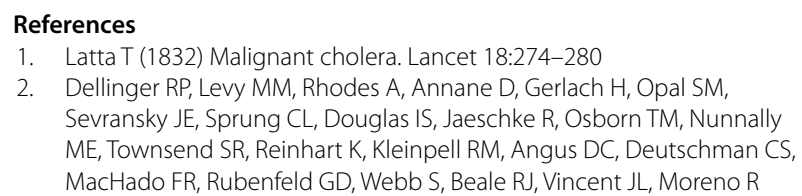

References MacHado FR, Rubenfeld GD, Webb S, Beale RJ, Vincent JL, Moreno R 
(2013) Surviving sepsis campaign: international guidelines for management of severe sepsis and septic shock, 2012. Intensive Care Med 39:165-228

3. Silversides JA, Major E, Ferguson AJ, Mann EE, McAuley DF, Marshall JC, Blackwood B, Fan E (2016) Conservative fluid management or deresuscitation for patients with sepsis or acute respiratory distress syndrome following the resuscitation phase of critical illness: a systematic review and meta-analysis. Intensive Care Med. doi:10.1007/s00134-016-4573-3

4. Silversides JA, Ferguson AJ, McAuley DF, Blackwood B, Marshall JC, Fan E (2015) Fluid strategies and outcomes in patients with acute respiratory distress syndrome, systemic inflammatory response syndrome and sepsis: a protocol for a systematic review and meta-analysis. Syst Rev 4:162

5. Cecconi M, Hofer C, Teboul JL, Pettila V, Wilkman E, Molnar Z, Della Rocca G, Aldecoa C, Artigas A, Jog S, Sander M, Spies C, Lefrant JY, De Backer D (2015) Fluid challenges in intensive care: the FENICE study: a global inception cohort study. Intensive Care Med 41:1529-1537

6. Bihari S, Baldwin CE, Bersten AD, Ou J, Holt AW, Prakash S, Schnetz E, Fartasch M, van den Heuvel I, Vlasselaers D, Wouters PJ, Milants I, Ellger B, Vanhorebeek I, Van den Berghe G (2013) Post resusicitation fluid boluses in severe sepsis or septic shock: prevalence and efficacy (price study). Crit Care Resusc 12:66-70

7. Hjortrup PB, Haase N, Bundgaard H, Thomsen SL, Winding R, Pettila V, Aaen A, Lodahl D, Berthelsen RE, Christensen H, Madsen MB, Winkel P, Wetterslev J, Perner A, CLASSIC Trial Group; Scandinavian Critical Care Trials Group (2016) Restricting volumes of resuscitation fluid in adults with septic shock after initial management: the CLASSIC randomised, parallel-group, multicentre feasibility trial. Intensive Care Med 42:1695-1705. doi:10.1007/s00134-016-4500-7
8. National Heart, Lung, and Blood Institute Acute Respiratory Distress Syndrome (ARDS) Clinical Trials Network, Wiedemann HP, Wheeler AP, Bernard GR, Thompson BT, Hayden D, deBoisblanc B, Connors AF Jr, Hite $\mathrm{RD}$, Harabin AL (2006) Comparison of two fluid-management strategies in acute lung injury. N Eng J Med 354(24):2564-2575

9. Malbrain ML, Marik PE, Witters I, Cordemans C, Kirkpatrick AW, Roberts DJ, Van Regenmortel N (2014) Fluid overload, de-resuscitation, and outcomes in critically ill or injured patients: a systematic review with suggestions for clinical practice. Anaesthesiol Intensive Ther 46:361-380

10. The ARISE Investigators and the ANZICS Clinical Trials Group (2014) Goaldirected resuscitation for patients with early septic shock. N Engl J Med 371:1496-1506

11. The ProCESS Investigators (2014) A randomized trial of protocol-based care for early septic shock. N Engl J Med 370:1683-1693

12. Mouncey PR, Osborn TM, Power GS, Da Harrison, Sadique MZ, Grieve RD, Jahan R, Harvey SE, Bell D, Bion JF, Coats TJ, Singer M, Young JD, Rowan KM, Pro MTI (2015) Trial of early, goal-directed resuscitation for septic shock. N Engl J Med 372:1301-1311

13. Maitland K, Kiguli S, Opoka RO, Engoru C, Olupot-Olupot P, Akech SO, Nyeko R, Mtove G, Reyburn H, Lang T, Brent B, Evans JA, Tibenderana JK, Crawley J, Russell EC, Levin M, Babiker AG, Gibb DM (2011) Mortality after fluid bolus in African children with severe infection. N Engl J Med 364:2483-2495

14. Michard F, Teboul JL (2002) Predicting fluid responsiveness in ICU patients: a critical analysis of the evidence. Chest 121:2000-2008 